\section{Forests: see the trees and the wood}

Silvano Fares and colleagues' recommendations for managing Europe's forests to promote resilience and carbon storage (Nature 519, 407-409; 2015) seem to overlook the implications for forests as natural ecosystems and run counter to biodiversity sustainability guidelines (D. B. Lindenmayer et al. Biol. Conserv. 131, 433-445; 2006). These must be taken into account if we are to meet the Convention on Biological Diversity's Aichi targets and the European Union's 2020 target for halting biodiversity loss.

For example, managing a forest's composition of tree species in favour of productive, gale-resistant and diseasetolerant species or genotypes will be at the expense of hundreds of native woody species and their rich biota of insects and fungi. Harvesting trees at shorter intervals to promote carbon storage would endanger old forests and veteran trees, along with the birds, bats, beetles, fungi and lichens they support. And removing woody debris to prevent wildfires would kill the wealth of species that thrive on dead and decaying wood.

Hans Henrik Bruun, Jacob Heilmann-Clausen University of Copenhagen, Denmark. Rasmus Ejrnæs Aarhus University, Denmark. hhbruun@bio.ku.dk

\section{Forests: not just timber plantations}

In considering how to develop Europe's forests sustainably (S. Fares et al. Nature 519, 407-409; 2015), it is important to differentiate between intensively managed forestry areas and forests as natural habitats. Working with, rather than against, nature is more likely to offer sustainable solutions (see, for example, the forest work programme of the Convention on Biological Diversity: www. cbd.int/forest), especially in view of the potential effects of climate change on European forests.

One of the targets in the European Union (EU) biodiversity strategy for 2020 calls for forestry management practices to improve the conservation status of species and habitats. Current forestry practices all too often do just the opposite (see, for instance, D. B. Lindenmayer et al. Biol. Conserv. 131, 433-445; 2006).

As the EU parliament debates a common forest strategy, we need to look beyond promoting intensive forestry for maximum timber yield under the flag of climate change. Forestry practices that preserve natural ecosystem processes are likely to be more effective in maintaining forests' biodiversity and natural resilience against climate change (see, for example, T. Kuuluvainen and R. Grenfell Can. J. For. Res. 42, 1185-1203; 2012).

Bengt Gunnar Jonsson

Mid Sweden University, Sundsvall, Sweden.

Guy Pe'er Helmholtz Centre for Environmental Research - UFZ, Leipzig, Germany.

Miroslav Svoboda Czech

University of Life Sciences, Prague, Czech Republic.

bengt-gunnar.jonsson@miun.se

\section{Research network to track alpine water}

The water cycle in alpine environments worldwide supplies fresh water to vast downstream areas inhabited by more than half of humanity. The International Network for Alpine Research Catchment Hydrology (INARCH) was launched this year by the Global Energy and Water Exchanges project of the World Climate Research Programme, to improve the predictability of water resources from mountainous regions (see www.usask.ca/inarch).

Melting snow and ice are altering hydrological systems and affecting the quantity and quality of water resources, as indicated in the 2014 Working Group II report by the Intergovernmental Panel on Climate Change. Insight into these processes has been limited by the difficulties of collecting data on the alpine water cycle in high-mountain research areas. Studies have been concentrated at few sites, with poor data comparison across mountainous regions.

INARCH's alpine catchments are well equipped to measure snow and ice hydrology. Such information can be used, for example, to investigate the effects of mountain snowpacks and glaciers on water supply, or to study variations in energy and water exchange in different high-altitude regions. The network will help to develop new observational methods, a measurement infrastructure and an international database to guide research and policy.

John Pomeroy University of Saskatchewan, Canada.

Matthias Bernhardt $B O K U$ University of Natural Resources and Life Sciences, Vienna, Austria. Daniel Marks US Department of Agriculture Agricultural Research Service, Boise, Idaho, USA. matthias.bernhardt@boku.ac.at

\section{Botanists still need to tell plants apart}

I disagree with Isabel Marques' frightening suggestion that botanical education should be 'modernized' by moving away from the study of specimens towards a more molecular approach (Nature 520, 295; 2015). Classical botanical disciplines such as systematics and taxonomy fail to attract students not because they lack molecular allure, but because of the time-consuming focus they demand.

In any case, many botany students at universities worldwide are also trained in molecular biology, as at my institute, the
University of Pretoria in South Africa, and at the Ruhr University Bochum in Germany, for instance. Even 'old-fashioned' studies in the field of plant systematics rarely get published without molecular data, and these often include genomic data.

Drawing botanical education away from the plant itself risks creating 'experts' who cannot reliably differentiate species. Marques' call for outreach to help the public to identify common plants would then not stand a chance.

Martin Kemler University of Pretoria, South Africa. martin.kemler@fabi.up.ac.za

\section{Interim initiative for health in Iran}

As physicians working in Iran, we agree that the lifting of economic sanctions cannot come soon enough for the nation's health (M. Aloosh and A. Aloosh Nature 520, 623; 2015). In the interim, a group dedicated to restoring Iran's medical science, public health and health diplomacy is launching a non-profit organization - the Iranian-American Partnership for Medical Science and Public Health Association (IAPA). The partnership is based in Switzerland and comprises US and Iranian volunteers (including myself).

One of IAPA's first priorities is to seek relief for young cancer patients in charity hospitals where chemotherapy drugs are in desperately short supply (see S. Shahabi Nature 520, 157; 2015). A channel for such humanitarian support was established in November 2013 by the Joint Plan of Action between Iran and six other countries, in part to address the unwanted consequences of international sanctions (see go.nature.com/nr1sfn).

Ali Akbar Velayati, Hamidreza Jamaati, Seyed Mohammadreza Hashemian Shahid Beheshti University of Medical Sciences, Tehran, Iran. iran.criticalcare@yahoo.com 